\title{
Actitudes hacia la justicia restaurativa en jóvenes vinculados al sistema de responsabilidad penal adolescente (SRPA)
}

Yohana Marcela Méndez GonZÁlez ${ }^{6}$

\section{Introducción}

Las medidas que se han implementado como respuesta al fenómeno social de vinculación por parte de jóvenes en actividades delictivas motivan a construir rutas de valoración y atención frente al contexto juvenil delincuencial. Para tal efecto, se diseñó y validó por jueces la escala de valoración de actitudes hacia la justicia restaurativa en jóvenes vinculados al Sistema de Responsabilidad Penal Adolescente que cumplen medida de privación de libertad. La escala alcanzó fiabilidad con el alfa de Cronbach $=0.899$ y un índice de razón de validez de contenido $(\mathrm{CVR})=0.73$. Los resultados del estudio denotan por un lado las altas cualidades psicométricas de la escala y por otro,

6 Psicóloga, Magíster en Psicología Jurídica de la Universidad Santo Tomás. Investigadora en contextos de jóvenes vinculados al Sistema e Responsabilidad Penal Adolescentes SRPA. Constructora de la Escala de Valoración de Actitudes hacia la justicia restaurativa. Actual Directora Ejecutiva y de Proyectos del Instituto de Neurociencias Aplicadas INEA en Bogotá. La correspondencia relacionada con este artículo debe ser dirigida a Yohana Méndez: Maestría en Psicología Jurídica Universidad Santo Tomás. Correo electrónico: yohanamendez87@gmail.com 
las posibilidades de desarrollar opciones interventivas en las que participe la triada: ofensor, víctima y comunidad en el desarrollo efectivo de programas en justicia restaurativa. De igual manera se concluyó a partir de los resultados obtenidos que los jóvenes presentan alta proclividad $95 \%$ frente a las actitudes hacia la justicia restaurativa, por tanto es pertinente generar programas en esta línea para la población vinculada al SRPA.

A partir de la Ley 1098 de 2006 por la cual se expide en Colombia el Código de Infancia y Adolescencia, se introdujo el Sistema de Responsabilidad Penal Adolescente (SRPA), el cual tiene una finalidad protectora, educativa y restaurativa para que los jóvenes que infrinjan la ley cuenten con mecanismos que les permitan reconocer el daño causado, su responsabilidad en el hecho y la necesidad de reparar a la víctima, además de contar al mismo tiempo con protección, restablecimiento de sus derechos y reintegración social. En ese sentido los operadores judiciales están en el proceso de contextualizarse frente a los procesos que propenden desde este marco, uno de ellos la justicia restaurativa, aquella que al igual que la mediación y la conciliación son procesos cooperativos y de colaboración, donde se busca la recuperación del sujeto para la sociedad más no la individualización de un culpable (Bañol \& Bañol, 2006).

Diversos estudios de política criminal han concluido que a mayor grado de sanción no hay menor grado de criminalidad, pues está demostrado por los índices de criminalidad, que el aumento de penas no es el mecanismo por medio del cual se abstienen las personas de realizar conductas al margen de la ley, por tanto, la justicia restaurativa en el escenario legal de acuerdo con Padilla (2012) se presenta como una estrategia a través de la cual los ciudadanos pueden intervenir en la construcción de una mejor sociedad mediante herramientas protectoras, pedagógicas y restaurativas de la sanción. En la misma línea, González (2009) señala que la justicia restaurativa ve los actos criminales de forma amplia, es decir, en vez de definir el crimen como una simple trasgresión de leyes, reconoce que los infractores dañan a las víctimas, a las comunidades y aún más a ellos mismos, por ende la justicia restaurativa involucra tanto a dichos actores, como a sus víctimas y a las comunidades, lo que permite evaluar de forma distinta el 
éxito de los programas, puesto que en vez de medir cuánto castigo fue infringido, mide cuantos daños son reparados o incluso prevenidos.

En ese sentido la psicología jurídica permite acercar el constructo de justicia restaurativa a los operadores del SRPA, al proponer rutas de intervención y formas de evaluación/aplicación, que permitan día tras día poner en práctica y con mayor conocimiento las posibilidades que según Padilla (2012) se han ido construyendo para los jóvenes frente al fenómeno de la delincuencia, como lo son por ejemplo: prestación de servicios a la comunidad, amonestaciones, reglas de conducta y libertad asistida, sanciones que se deben priorizar antes de las privativas de la libertad acorde al caso, por eso entender a qué se refiere la justicia restaurativa es fundamental.

En el año 2002, la justicia restaurativa fue definida por la Organización de las Naciones Unidas (ONU) como una respuesta evolutiva al delito, que respeta la dignidad y la igualdad de todas las personas, favorece el entendimiento y promueve la armonía social mediante la recuperación de las víctimas, los delincuentes y las comunidades; de igual forma es un proceso en el que la víctima, el delincuente y cuando proceda, cualesquiera otras personas o miembros de la comunidad afectados por un delito, participan de forma activa en la resolución de cuestiones derivadas del delito, por lo general con la ayuda de un facilitador; lo anterior indica que la justicia restaurativa, establece, como lo plantea Hernández (2011), un nuevo paradigma, centrado más en la reparación que en el castigo; siendo una forma alternativa de solución de conflictos legales, como lo señalan Díaz y Gutiérrez (2008), que ha cobrado importancia en el mundo actual, desde la aparición del movimiento victimológico y desde la necesidad de crear formas novedosas de respuesta al paradigma retributivo tradicional del sistema penal.

Este contexto sobre la justicia restaurativa implica pensar en su foco principal de aplicación que acorde con esta investigación son los jóvenes vinculados al SRPA, y quienes pueden ser definidos desde la propuesta realizada por Cruz en el 2007 quien señala que los jóvenes infractores o transgresores de la norma, son personas que tienen menos de 18 años y que realizan conductas tipificadas como delitos por las leyes penales vigentes, no siendo aplicable al caso del adolescente la noción de pena 
como consecuencia del acto ilícito, por no poderse acreditar su conducta antijurídica como delito, es por ello que surge la necesidad de someterles a un régimen especial de atención el cual debe buscar adicionalmente protegerlos o tutelarlos.

En un estudio realizado por Álvarez (2007) en las principales ciudades de Colombia, a saber: Bogotá, Cartagena, Barranquilla y Medellín, evidenció en sus resultados que el $89 \%$ del problema se centra sobre todo en carencias de tipo afectivo y a su vez encontró que la motivación de los adolescentes para infringir la ley correspondía principalmente con la necesidad de tener dinero $16 \%$, con el consumo de sustancias psicoactivas $15 \%$, con la sobrevivencia y un porcentaje alto $25 \%$ señalan no tener una motivación definida para infringir la ley, encontrándose finalmente la venganza 9\%, la curiosidad, el honor, motivos pasionales, el reconocimiento y otros factores entre el $3 \%$ y el $2 \%$ respectivamente. Lo anterior presenta un amplio espectro que permite observar la multicausalidad del fenómeno de la delincuencia juvenil. De igual manera, en el estudio Álvarez (2007) señaló que al parecer existen una serie de características que son necesarias para la supervivencia del joven que construye su vida a partir del conflicto con la ley, características como: el no expresar emociones, el ser observador, desconfiado y manipulador, todas ellas conjugadas con falencias heredadas de un proceso educativo deficiente, como el orden ausente para construir un plan de vida y el despilfarrar los recursos y ganancias rápidamente en gustos personales. El anterior estudio le permitió presentar los principales delitos cometidos a nivel nacional por jóvenes que han trasgredido la ley y se encuentran vinculados al SRPA. 
Figura 1. Espectro de delitos cometidos por los niños y adolescentes infractores de la ley penal.

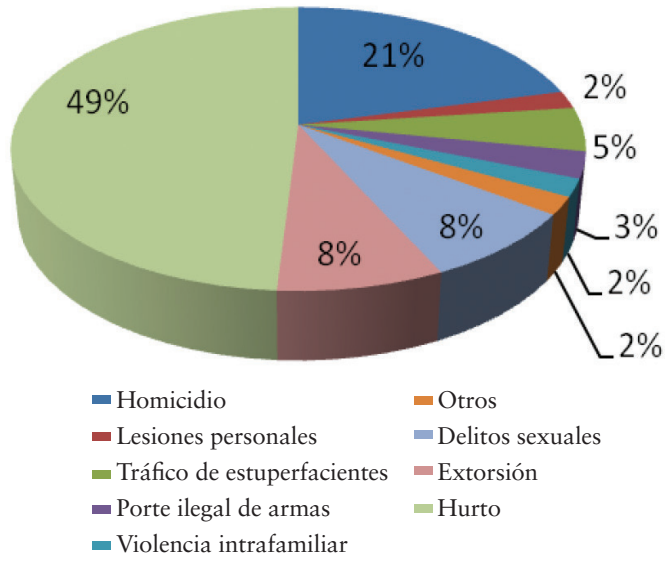

Fuente: Álvarez, 2017.

Es un hecho lamentable y cada día más frecuente evidenciar el aumento de jóvenes que están iniciando y desarrollando actividades delictivas, jóvenes que encuentran un sentido de inclusión en estos actos pues a pesar de ser ilícitos les proveen sentido, identidad y vínculo en medio de un contexto poco favorable, pues tal como lo señalan Vélez y Martínez (1999) el problema de la delincuencia juvenil y de sus nuevas formas de expresión es multicausal, hunde sus raíces en la cultura actual excluyente y marginal en la que cada vez más jóvenes quedan privados de los mínimos derechos de tipo económico, político, social y personal; favoreciendo sentimientos de angustia, resentimiento e impotencia que llevan a los jóvenes al enfrentamiento en contra de un sistema social injusto con las implicaciones que de ello resultan. Por tanto, como lo señala Cyrulnik (2002) la delincuencia comienza a ser vista por el joven como una forma de decisión e inclusión ante un medio socio-cultural poco favorable y en transformación, ya que en este contexto es una opción que adquiere un valor adaptativo.

Este fenómeno se está configurando como mayor impacto en contextos de vulnerabilidad de la población colombiana, a partir de situaciones que inciden en una postura de riesgo y poca favorabilidad hacia los jóvenes, condiciones tales como: la baja escolarización, el 
desempleo, la pobreza, la corrupción, la delincuencia, la negligencia y la falta de inversión por parte del Estado, inversión que de acuerdo con Álvarez (2007) es reducida para la juventud y es necesaria para plantear con mayor espacio dentro de las políticas públicas; lo cual implica la necesidad de aumentar la inversión de presupuestos en programas que impacten a la población juvenil, posibilitando así, su vinculación a distintos escenarios de participación comunitaria y local. Ejemplo de cómo abordar y atender esta necesidad lo da el Plan Estratégico de Desarrollo Juvenil (PEDJ) enmarcado para los años 2011 a 2020, en donde se condensa la política pública de la juventud de Cundinamarca; un plan que denota el esfuerzo por atender la juventud desde la política pública señalando sus principales directrices aquellas que han ido emergiendo luego de un proceso de investigación construido con la población de jóvenes, que permite ofertar programas y proyectos respondiendo a la necesidad que tienen como grupo poblacional frente a su formación como talento humano, fortaleciendo las instituciones a las cuales pertenecen y desarrollando alianzas estratégicas y de cooperación empresarial que permitan incluir a los jóvenes en contextos laborales, potenciando a su vez su participación en ambientes académicos a través de herramientas técnicas y pedagógicas que promuevan su aprendizaje. Un plan que en resumen propende por los derechos de la juventud y porque los programas que se generen tengan como objetivos esenciales la promoción de sus derechos.

Por tanto, con el fin de comprender y medir la viabilidad de generar proyectos basados en justicia restaurativa, para jóvenes vinculados al sistema de responsabilidad penal adolescente en condición de privación de libertad, se propuso la construcción de la "Escala de valoración de actitudes hacia la justicia restaurativa", es por esto que se considera relevante acercarse al constructo, por ejemplo, existen múltiples definiciones sobre las actitudes como la expuesta por Schultz y Schultz (2013) quienes afirman que las actitudes tienen un objeto de referencia específico, es decir se tienen actitudes hacia algo y estas son positivas o negativas, están a favor o en contra de ese algo, llevan a la simpatía o al odio, a aceptar o rechazar o a acercarse a un objeto o evitarlo, en este caso la justicia restaurativa. Por su parte Vázquez \& 
Manassero (1995) relacionan el concepto de actitud comúnmente con el de disposición, que se operacionaliza en el interés, la motivación, el agrado y la buena disponibilidad demostrada junto con la atención, es un constructo que desde su perspectiva está relacionado con los procesos que se pueden identificar en niveles académicos, que implican procesos de enseñanza aprendizaje.

Ahora, para los efectos del presente estudio, se entiende la actitud hacia la justicia restaurativa como una predisposición aprendida para responder coherentemente de manera favorable o desfavorable ante un objeto, un ser vivo, una actividad, concepto, persona o sus símbolos, (Hernández, Fernández \& Baptista, 2006; Méndez \& Peña, 1994) en este caso hacia la justicia restaurativa, la cual es respuesta evolutiva al delito que respeta la dignidad y la igualdad de todas las personas, favorece el entendimiento y promueve la armonía social mediante la recuperación de las víctimas, los delincuentes y las comunidades; de igual forma es un proceso en el que la víctima, el delincuente y cuando proceda, cualesquiera otras personas o miembros de la comunidad afectados por un delito, participan de forma activa en la resolución de cuestiones derivadas del delito, por lo general con la ayuda de un facilitador (ONU, 2002).

A su vez, es importante señalar que para el desarrollo de esta investigación se consultó la existencia de instrumentos que midieran actitudes hacia la justicia restaurativa y fuentes de estudios relacionados, encontrándose algunos aunque con un nivel de medición distinto, un ejemplo de dichas fuentes es la escala de aceptación a la justicia restaurativa, elaborada por Frias, Duron \& Castro (2011) para un estudio de la evaluación de los factores comunitarios de la justicia restaurativa, donde se conformaron escalas que medían: empatía, emocionalidad, cohesión social, liderazgo, intolerancia y aceptación de la justicia restaurativa. La escala contenía preguntas sobre la posibilidad de que la gente participe en los procesos restaurativos con cuestiones como "los líderes de barrio pudieran funcionar como mediadores entre las víctimas y los jóvenes", “si los jóvenes reparan el daño ya no deben ser detenidos", entre otras; se media puntuando una escala de 0 al 10 en donde 0 indica en total desacuerdo y 10 totalmente de acuerdo. El alfa que presenta esta escala es de $0.77 \mathrm{y}$ 
los resultados indicaron que las actitudes positivas hacia la justicia restaurativa estaban predichas positivamente por la capacidad de liderazgo y negativamente por la intolerancia, lo que muestra una relación entre los recursos personales y la predisposición a desarrollar actitudes hacia la justicia restaurativa; por tanto teniendo este marco de referencia se consideró pertinente la construcción de la Escala de Actitudes hacia la Justicia Restaurativa (EVAJR).

\section{Método}

\section{Participantes}

Para obtener los resultados en esta investigación se trabajó con un grupo de 21 jóvenes vinculados al SRPA que se encuentran entre los 16 y 21 años de edad, quienes han sido remitidos por el juez de conocimiento para el cumplimiento de la sanción impuesta (privación de la libertad) todos a quienes por la gravedad del delito se les programa un periodo de tiempo que excede la mayoría de edad pero no supera los 21 años en Bosconia, institución que trabaja solamente género masculino en su programa de reeducación y que se encuentra adscrita al Centro Educativo Amigoniano (CEA) donde se oferta un programa de reeducación y atención integral que les facilita a los jóvenes la convivencia social y les permite mejorar su calidad de vida al tiempo que se encarga del cumplimiento de su función resocializadora. Propiamente para la aplicación del pilotaje participó un grupo de 42 jóvenes, el tipo de muestreo implementado fue de participantes voluntarios, quienes se encuentran internos en la Institución Bosconia en la ciudad de Bogotá.

\section{Tipo de estudio}

El alcance de la investigación en la que se circunscribió el presente estudio utilizó metodología cuantitativa y un diseño comparativo el cual pretendió evaluar las actitudes hacia la justicia restaurativa en los jóvenes que se encuentran vinculados al Sistema de Responsabilidad 
Penal Adolescente SRPA en la institución Bosconia del CEA en Bogotá. Es un estudio comparativo que tal como lo señala Kazdin (1986), es un método que a través del uso de técnicas psicosociales permite contrastar datos que bien pueden provenir de la aplicación de determinados tratamientos, estrategias de intervención para producir cambios psicológicos o sociales, o bien contrastar conceptos, teorías, focos de intervención, entre otros. De igual manera fue un estudio aprobado y avalado por parte del Comité Directivo del Centro Educativo Amigoniano y la Escuela de Trabajo el Redentor, al estimar viable y necesaria su aplicación y resultados con el fin de orientar rutas de intervención con base en los resultados a obtener.

\section{Instrumento}

Para desarrollar el objetivo de esta investigación se construyó y validó la "Escala de valoración de actitudes hacia la justicia restaurativa" (EVAJR) (Anexo 1). Esta escala contempló inicialmente un apartado de datos socio - demográficos, una pregunta acerca de si se conoce o no sobre el significado de justicia restaurativa y una escala tipo likert que permite medir las actitudes hacia la justicia restaurativa del evaluado a partir de la lectura de situaciones posteriores a su condición de privación de libertad. Cuenta con 34 ítems que permiten que el evaluado señale su grado de acuerdo con el ítem a través de 4 opciones de respuesta a saber: totalmente de acuerdo, de acuerdo, en desacuerdo y totalmente en desacuerdo con cada uno de los ítems que presentan afirmaciones de su forma de proceder en la vida, dando como resultado su nivel de actitudes hacia la justicia restaurativa. Los rangos de calificación de acuerdo a los resultados obtenidos con el instrumento se transforman de puntuación bruta a puntuación percentilar a través de la siguiente formula $((x-34) / 102) * 100)$, donde $\mathrm{x}$ es el puntaje bruto obtenido por el participante. El puntaje resultante de esta fórmula ya transformado a percentiles se clasifica en tres rangos de actitudes hacia la justicia restaurativa a saber: bajo (0-70), medio $(71-89)$ y alto (90 a 100).

Inicialmente, se elaboraron 80 ítems que fueron perfeccionados por la investigadora junto con la directora del proyecto de investigación 
hasta llegar a 54 ítems, posteriormente se convocaron cuatro jueces expertos considerando su formación académica, su reconocimiento en la comunidad científica y su experticia tanto en el tema de estudio, como en medición y evaluación y se diseñó un instrumento con el fin de evaluar 5 criterios frente a los ítems que medían el constructo de actitudes hacia la justicia restaurativa a saber: claridad, pertinencia, suficiencia, ubicación y relación con el constructo; dejando un espacio para generar observaciones adicionales que surgieran frente a los ítems (Anexo 2). Se implementó también el índice cuantitativo CVR (Content Validity Ratio), que es un modelo de validez de contenido de los instrumentos psicológicos propuesto por Lawshe (1975), adaptado por Tristán (2008), este modelo con el fin de hacer el proceso de validez de contenido del instrumento construido en actitudes hacia la justicia restaurativa; en este modelo se destaca que la razón de validez de contenido debe ser igual o mayor a 0.5823 para tener significancia y ser incluido como ítem en la escala. Los datos de la información obtenida se trabajaron a través del Statistical Package for the Social Sciences, denominado SPSS (Gardner, 2003).

Al ser calculados los resultados del proceso a través del índice de Razón de Validez de Contenido (CVR) se obtuvieron para análisis los ítems que alcanzaron una puntuación por debajo de 0.58 para ser eliminados. Se tuvieron entonces 47 ítems que superaron la validez de contenido y 7 que no $(21,31,33,36,39,40,50)$ de los cuales se eliminaron $(36,39,40)$ y se modificaron $(21,31,33,50)$. Algunos de los ítems que se debían eliminar se ajustaron y los otros fueron eliminados por redundancia con relación a otros ítems del cuestionario construido, quedando el instrumento con 39 ítems en este procedimiento. Por tanto, luego de realizar el proceso con los 54 ítems bajo el modelo propuesto, se encontraron 7 ítems con valores CVR por debajo de 0,58 a saber 21, 31, 33, 36, 3940 y 50, los cuales fueron eliminados; el resto de los ítems se encontraba por encima de ese valor. Siendo así el Índice de validez de contenido de todo el instrumento $=0,73$, teniendo en cuenta CVR 1: $\sum$ CVR $1=39,67 \sum$ CVR $1 / 54=0.73$

Una vez realizado el proceso con los jueces expertos con el instrumento de 54 ítems y el índice de validez de contenido del instrumento, se eliminaron los ítems que no cumplieron el criterio $(36,39$ y 40$)$ y se 
eliminaron también los ítems $(7,9,19,24,25,35,42,43,44,45,46$ y 52 ) a discreción del investigador por redundancia en contenido, quedando el instrumento conformado por 39 ítems, se continuó el pilotaje del instrumento aplicándolo a 42 jóvenes y se evidenció la necesidad de eliminar 3 ítems debido a que era posible realizar doble interpretación de las afirmaciones (18, 28 y 31), quedando entonces 36 ítems frente a los cuales se aplicó el Alfa de Cronbach, dando como resultado 0,891 y luego de este proceso de análisis de confiabilidad de datos, se eliminaron dos ítems que presentaban una correlación menor a 0,2 (13 y 30) quedando el instrumento final con un total de 34 ítems y un Alfa de Cronbach final de 0,899, un índice de confiabilidad bastante alto para evaluar actitudes hacia la justicia restaurativa.

\section{Resultados}

En la presente investigación se contó con una población de 21 participantes, a nivel socio demográfico la mayoría $(80,95 \%)$ reportó en su estado civil la condición de soltero; sus edades oscilaron entre los 16 y los 20 años, encontrándose la mayoría a punto de cumplir 18 años $(47,62 \%)$, con relación a su ciudad de origen el $85,71 \%$ provenían de Bogotá, el porcentaje restante provenían de Arauca, Neiva y Tunja, sin embargo sus sistemas familiares estaban radicados en Bogotá, lo cual posibilita que el joven cuente con al acompañamiento de su sistema familiar. Todos los participantes del estudio reportaron tener hermanos, en promedio 2 o 3 con el 52,38\%, el resto reportaron tener entre uno y once hermanos; el lugar que ocupan con relaciona a sus hermanos con mayor probabilidad es el del medio o tercero con un $19,05 \%$ y un $23,81 \%$ respectivamente. El estrato social predominante es el 2 donde se ubica el 52,38\% de los participantes, seguido por el 3 con un 33,33\% y el 1 con un 14,29\%, no se encontraron reportes de pertenencia a los estratos 4, 5 o 6; ahora, con relación a las localidades en las que residían los participantes antes de encontrarse privados de la libertad, se encuentra una distribución uniforme en la zona sur de Bogotá, varias localidades con el 4,76\%, resaltándose 
Bosa y Kennedy con el 14,29\%, en la zona norte destacándose Suba y Usaquén con igual porcentaje $14,29 \%$ y en la zona central Chapinero con un $4,76 \%$.

En cuanto al nivel educativo de la población se observó que el $76,19 \%$ de los jóvenes se encontraba en bachillerato, en promedio en grado noveno, condición educativa que reconoce la institución especializada en la privación de libertad (CEA, 2009) por tanto, durante el tiempo que permanece cada uno de los jóvenes cumpliendo la sanción impuesta por el juez, la institución garantiza el derecho a la continuidad académica al interior de la institución. Por su parte, el 4,76\% de los jóvenes se encontraba en instituciones de educación técnica, porcentaje bajo ya que de acuerdo con las edades de los jóvenes se podrían encontrar en un nivel de educación superior o técnico. Finalmente se encuentra un 19,05\% de jóvenes que a pesar de su edad se encuentran cursando primaria, algunos de ellos los cuales han abandonado sus estudios desde hace dos o tres años y han retomado su proceso educativo una vez ingresan al programa de reeducación, lo que indica que en el contexto previo a su institucionalización, se encontraban en condición de vulnerabilidad y riesgo al no estar en ambientes educativos acordes con su edad, siendo proclives a encontrarse en la calle y realizar actividades delictivas, aquellas por las cuales se encuentran privados de la libertad, por tanto esta medida a su vez permite que se le restituyan los derechos a estos jóvenes tal como lo señala la Ley 1098 de 2006 en su artículo No. 19 del derecho a la rehabilitación y a la resocialización y en su artículo No 28 del derecho a la educación.

Por su parte, los resultados de la Escala frente a las actitudes hacia la justicia restaurativa fueron establecidos con las puntuaciones en tres rangos los cuales fueron: Bajo con puntuaciones de 1 a 70, Medio con puntuaciones de 71 a 89 y Alto con puntuaciones de 90 a 100. Las puntuaciones promedio en la Escala fueron de $\mathrm{X}=83,24$ con una desviación estándar de $\mathrm{S}=10,76$ 
Figura 2. Resultados por rangos en la "Escala de actitudes hacia la justicia restaurativa"

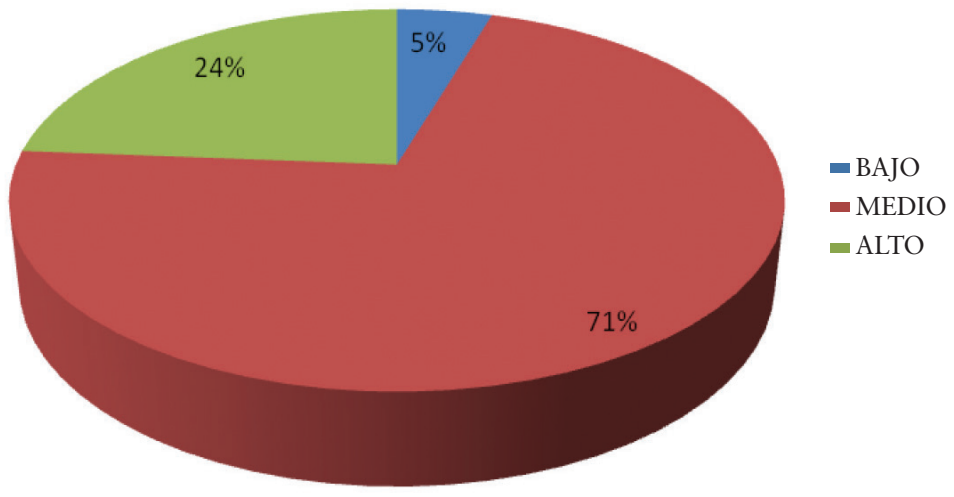

De acuerdo a la gráfica es posible evidenciar que el 71\% de la población presentaba un nivel medio de actitudes hacia la justicia restaurativa y el $24 \%$ presentaba un nivel alto, también se encontró un $5 \%$ que presentaba bajos niveles frente a las actitudes hacia la justicia restaurativa.

En promedio se identifica que más de la mitad de la muestra participante obtuvo un resultado proclive frente a las actitudes hacia la justicia restaurativa 95\% (nivel medio y alto), lo cual indica que pueden realizarse proyectos que faciliten y potencien el desarrollo de procesos en justicia restaurativa, donde a los jóvenes se les presenten alternativas que les permitan direccionar nuevas acciones frente al delito cometido, reconociendo el impacto generado en la víctima y el aporte que a nivel comunitario también pueden recibir e implementar. Este es un marco de desarrollo para los procesos que promueve la psicología jurídica en el sistema de responsabilidad penal para adolescentes, teniendo en cuenta los alcances de la Ley 1098 de 2006.

Finalmente, con relación a las preguntas que contiene la "Escala de valoración de actitudes hacia la justicia restaurativa frente a si conoce o no el significado de la justicia restaurativa se obtuvieron respuestas de las cuales fue posible construir dos categorías emergentes que se evidenciaban en las respuestas de los jóvenes, a saber: reparación y reconocimiento. 
Figura 3. Categorías emergentes con relación al significado de justicia restaurativa dado por los jóvenes del estudio

\begin{tabular}{|l|l|l|}
\hline \multicolumn{2}{|c|}{ Reparación } & \multicolumn{1}{c|}{ Reconocimiento } \\
\hline $\begin{array}{l}\text { "Reparar ante la } \\
\text { justicia todos los } \\
\text { daños que he llegado a } \\
\text { cometer" }\end{array}$ & $\begin{array}{l}\text { "Restaurar el daño } \\
\text { causado a la víctima o } \\
\text { haciendo prevención } \\
\text { con la sociedad" }\end{array}$ & $\begin{array}{l}\text { "Reconocer y responder por } \\
\text { nuestros actos cometidos" }\end{array}$ \\
\hline $\begin{array}{l}\text { "Es reparar el daño } \\
\text { causado para que no } \\
\text { se vuelva a cometer" }\end{array}$ & $\begin{array}{l}\text { "Restaurar el daño } \\
\text { causado a la víctima o } \\
\text { aquella persona que se } \\
\text { ha hecho daño" }\end{array}$ & $\begin{array}{l}\text { "Remediar el daño causado } \\
\text { por nuestros errores } \\
\text { cometidos" }\end{array}$ \\
\hline $\begin{array}{l}\text { "Es la forma de } \\
\text { reparar los daños } \\
\text { causados a nivel } \\
\text { personal y social" }\end{array}$ & $\begin{array}{l}\text { "Es restaurar el daño } \\
\text { de una manera positiva } \\
\text { sin llegar a una } \\
\text { agresión" }\end{array}$ & $\begin{array}{l}\text { "Cuando uno tiene } \\
\text { la capacidad de } \\
\text { responsabilizarse de sus } \\
\text { actos" }\end{array}$ \\
\hline
\end{tabular}

Las categorías emergentes evidencian un acercamiento a la definición de la justicia restaurativa, que si bien está encausada principalmente a nivel personal, plantea el reconocimiento de algunos elementos base del concepto; lo anterior permite evidenciar la pertinencia de construir programas de capacitación que propendan por la formación en justicia restaurativa y en las diferentes estrategias que desde JR se plantean para construir alternativas a partir del reconocimiento de la relación entre el ofensor, la víctima y la comunidad con el fin de reparar el impacto del delito causado y principalmente lograr que el joven transgresor reconozca su responsabilidad en el delito cometido y sus posibles formas de reparación.

\section{Discusión}

En el estudio se realizaron análisis de validez y confiabilidad para corroborar la idoneidad psicométrica de la "Escala de valoración de actitudes hacia la justicia restaurativa", de la cual se puede afirmar que en efecto mide lo que pretende medir, ya que obtuvo un Índice de 
Validez de Contenido de 0,73 es decir válido pues su punto de inicio debe ser mínimo de 0,60. Por su parte, en términos de confiabilidad, entendida como el grado de consistencia que posee la Escala de medición obtuvo un Alfa de Cronbach final de $(0,899)$, lo que indica que la escala es útil y pertinente para aplicarla en programas donde se deseen conocer el nivel de actitudes hacia la justicia restaurativa, reconociendo su adecuada construcción y sus altas cualidades psicométricas.

Esta Escala (EVAJR) se ofertará como resultado de esta investigación para ser un recurso institucional que permita a través de sus resultados obtener mediciones de los grupos, de sus actitudes frente a los procesos propuestos desde la justicia restaurativa e incluso que permita medir los rangos en los grupos con los que se deseen construir programas de justicia restaurativa. Además de coadyuvar en la dirección de métodos alternativos de solución de conflictos MASC, que tal como los define Escudero (2007), son herramientas jurídicas mediante las cuales se permite solucionar controversias, sin tener que acudir a los mecanismos ordinarios establecidos en las leyes a cargo de los jueces, por tanto será un instrumento que pretende ser útil a la hora de orientar procesos desarrollados en esa línea de trabajo desde la justicia restaurativa con los jóvenes.

Frente a los datos obtenidos socio demográficos es posible concluir que en su mayoría es una población de jóvenes que presentan características que hacen que el grupo se ubique en un rango característico en aspectos tales como: su condición de ser solteros, tener el total de la población hermanos y en su mayoría ubicarse en la posición de ser el hermano del medio, pertenecientes al estrato 2 en su mayoría, seguidos del 1 y 3 y ubicando por fuera del espectro a jóvenes ubicados en estratos 4, 5 y 6 para la población con la que se trabajó en el estudio. Esta condición social vulnerable, aunada a sus respuestas del significado posible del concepto de justicia restaurativa, permite plantear la construcción de programas que trabajen con la población en la sensibilización y capacitación en justicia restaurativa, su significado, sus estrategias y las posibilidades que desde allí se pueden construir entre la triada ofensor, víctimas y comunidad. Posibilidades que les van a permitir a los jóvenes responsabilizarse frente al daño causado, reconocer 
el impacto que generó su delito y construir de manera conjunta posibles opciones de reparación. Lo anterior con base en los resultados obtenidos, permiten concluir que hay proclividad $(95 \%)$ por parte de los jóvenes frente a las actitudes hacia la justicia restaurativa y el desarrollo de programas en esta línea.

En esta investigación, los motivos principales por los cuales se encontraron institucionalizados los jóvenes cumpliendo una medida de privación de libertad fueron el hurto y el homicidio, motivos que presentó Álvarez en su investigación sobre instituciones de reeducación en el año 2007, puntuando los mismos delitos como base del ingreso por parte de los jóvenes a cumplir una medida de privación de libertad en las principales ciudades del país. Siendo así, la comparación en porcentajes de la investigación desarrollada mostró lo siguiente: para el delito de hurto se presentó un $49 \%$ frente a un $23,81 \%$ resultante en esta investigación y para el delito de homicidio se presentó un $21 \%$ frente a un $19,05 \%$ respectivamente, lo que indica que se mantiene una tendencia estable en los dos motivos principales de institucionalización al ser los delitos con mayor porcentaje de representación en la muestra de jóvenes, de allí la importancia de generar proyectos que trabajen temas que de manera preventiva les permitan a los jóvenes (o estudiantes en las instituciones educativas) desarrollar valores para afrontar la vida con competencias a todo nivel y que estos saberes les posibiliten proyectarse en el futuro, sea cual sea su condición social, contexto y los grupos a los cuales pertenezcan.

El 85,71\% de los jóvenes que participaron en la muestra reportaron estar por primera vez institucionalizados dando cumplimiento a la medida de privación de libertad, mientras que el 14,29\% reportaron haber estado antes en una institución de reeducación; estos datos otorgan elementos de soporte para la construcción de programas desde la justicia restaurativa pues tal como lo afirma una de las conclusiones del estudio sobre el impacto de la justicia restaurativa en la reincidencia juvenil presentado por Rodríguez (2007), los jóvenes que participan en un programa de justicia restaurativa son menos propensos a reincidir que los menores del grupo de comparación y aquellos con registros de antecedentes penales mínimos exhiben mayor éxito de participación en este tipo de programas. 
Por último, se señala que es de vital importancia que al vincular a jóvenes en los programas de justicia restaurativa se desarrolle un proceso en el cual se puedan buscar diferentes estrategias que permitan filtrar a sus participantes para que trabajen aquellos quienes pueden ser proclives al mismo y puedan estar interesados a desarrollarlo, trabajando por medio de acciones personalizadas, con el fin de que se pueda reconocer el objetivo del programa, sus implicaciones y lo que se espera, lo anterior basándose en que la intervenciones efectivas en este tipo de programas y poblaciones inician con un compromiso personal por parte del trasgresor, un compromiso deseado en el cual se constituye el programa como una estrategia misma para afrontar las consecuencias del daño causado y las implicaciones que a nivel personal, familiar y social se han generado; para lo cual se deja la Escala EVAJR como un primer eslabón en este importante proceso.

Finalmente, para continuar en la línea de este estudio sería muy interesante que se elabore un programa de capacitación en el cual se desarrolle un programa de sensibilización y capacitación en justicia restaurativa que permita a través de diferentes estrategias y a lo largo de determinadas sesiones acercar a los jóvenes con el concepto, brindarles la posibilidad de reconocer los alcances de la justicia restaurativa y que incluso se realicen ejercicios de primer acercamiento víctima - ofensor con el apoyo de un mediador, experto en psicología jurídica que permita encauzar el proceso y desarrollar los primeros escenarios efectivos al interior del Sistema de Responsabilidad Penal Adolescente SRPA. Lo anterior permitirá contar con resultados que permitan seguir profundizando en esta área en desarrollo desde la justicia restaurativa.

\section{Referencias}

Álvarez, M. (2007). Pescadores de ilusiones. Niños y jóvenes infractores de la ley penal. Bogotá: Instituto de estudios del Ministerio Público, Procuraduría General del Nación. 
Bañol, A y Bañol, L. (2006). Justicia restaurativa: una dinámica social. Colombia. Librería Jurídica Sánchez R. LTDA.

CEA. Centro Educativo Amigoniano. (2009). Pacto de Convivencia del centro de internamiento preventivo especializado y centro de atención especializado para la privación de la libertad, Escuela de Trabajo El Redentor. Bogotá: ETER

Cyrulnik, B. (2002). Los patitos feos: La resiliencia una infancia infeliz no determina la vida. España: Gedisa.

Cruz, E. (2007). El concepto de menores infractores. Revista del Posgrado en Derecho de la UNAM, 3(5), 335-355. Recuperado de http://www.juridicas.unam.mx/publica/ librev/rev/posder/cont/5/cnt/cnt17.pdf

Díaz, F y Gutiérrez, C. (2008). Aproximaciones a la justicia restaurativa ISNN 1692-0759. Asociación Latinoamericana de Psicología Jurídica y Forense. Recuperado el 15 de mayo de 2012 de http://psicologiajuridica.org/archives $/ 2330$

Escudero, M. (2007). Mecanismos alternativos de solución de conflictos. Conciliación, arbitramento y amigable composición. Bogotá: Ed. Leyer.

Frias, A., Duron, F \& Castro, D. (2011). Justicia restaurativa: Evaluación de los factores comunitarios. México. Revista Mexicana de Psicología, 28, 217 225. Recuperado de: http://www.redalyc.org/pdf/2430/243029631010.pdf

Gardner, C. (2003). Estadística para psicología usando SPSS para Windows. México: Prentice Hall.

González, A. (2009). La justicia restaurativa y el incidente de reparación en el proceso penal acusatorio. Bogotá. Leyer.

Hernández, R., Fernández, C. y Baptista, P. (2006) Metodología de la investigación. México D.F: Mc Graw Hill.

Hernández, G. (2011). Psicología Jurídica Iberoamericana. Bogotá: Manual Moderno.

Kazdin, A. (1986). Comparative Outcomes Studies of Psychotherapy: Mythological Issues and Strategies. Journal of Consulting and Clinical Psychology, 1, 95-105.

Ley 1098. (2006). Código de la Infancia y Adolescencia. Colombia

Méndez, L., y Peña, J. (1994). Manual práctico para el diseño de la escala likert. Universidad Autónoma Nuevo León - México: Trillas 
Organización de Naciones Unidas, ONU. (2002). Comisión de prevención del delito y Justicia Penal. Consejo económico y Social. Suplemento No 10. Recuperado el 14 de septiembre de 2012 de la página de las naciones unidas, documentos oficiales en la dirección http://www.ilanud.or.cr/ Informe $\% 2011 \% 20$ Periodo $\% 20$ Comisi $\%$ C3\%B3n \%20Delito

Padilla, A. (2012). La prestación de servicios a la comunidad: Una sanción con oportunidades para desarrollar procesos de justicia restaurativa en el sistema colombiano de responsabilidad penal para adolescentes. Colombia. Alcaldía Mayor de Bogotá.

PEDJ. (2011). Plan Estratégico de Desarrollo Juvenil 2011-2020. Política Pública de Juventud de Cundinamarca. Ordenanza 20 de 2007. Colombia. Recuperado de: file://C:/ Documents\%20and\%20Settings/ Usuario\%20Final/Mis\%20documentos/Downloads/PEDJ_2011_2020_ Cundinamarca.pdf

Schultz, D., \& Schultz, S. (2013). Teorías de la Personalidad. México. Cengage Learning.

Unicef. (1990). Convención sobre los derechos del niño. Recuperada de la página de Unicef el 10 de mayo de 2012 de http://www.unicef.org/spanish/crc/.

Rodríguez, N. (2007). Restorative Justice at Work: Examining the Impact of Restorative Justice Resolutions on Juvenile Recidivism. Arizona. Crime \& Delinquency, 53. 355-379. Recuperado de: http://cad.sagepub.com/ content/53/3/355.short\#cited-by

Vázquez, A. \& Manassero, M. (1995). Actitudes relacionadas con la ciencia: una revisión conceptual. Palma de Mallorca. Enseñanza de las Ciencias, 13(3), 337-346.

Vélez, C y Martínez, A. (1999). Pedagogías frente al conflicto social y educativo. Tomo II. Colombia: Fundación Universitaria Luis Amigó.

Tristán, A. (2008). Modificación al modelo de Lawshe para el dictamen cuantitativo de la validez de contenido de un instrumento objetivo. Instituto de Evaluación e Ingeniería Avanzada, México. Avances en Medición, 6, 37-48, retomado el 8 de noviembre de 2014 de http://www.humanas. unal.edu.co/psicometria/files/8413/8574/6036/Articulo4_Indice_de_validez_de_contenido_37-48.pdf \%201975.pdf 


\section{Anexo 1}

\section{Apéndice A. Escala de valoración de actitudes hacia la justicia restaurativa (EVAJR)}

Nombre:

Inicialmente deseamos agradecer su valiosa participación en este proceso.

A continuación encontrará una serie de preguntas, las cuales deberá relacionar con su forma cotidiana de responder ante diversas situaciones en la vida.

La forma de respuesta frente a estas preguntas se puede dar de acuerdo a cuatro categorías:

\section{Totalmente en desacuerdo}

2. En desacuerdo

3. De acuerdo

4. Totalmente de acuerdo

Por favor ahora diligencie sus datos personales y en la hoja siguiente marque con una $(\mathrm{X})$ según corresponda con la respuesta que más se acerca a su forma de responder cotidianamente.

\section{DESCRIPCIÓN}

OBSERVACIONES

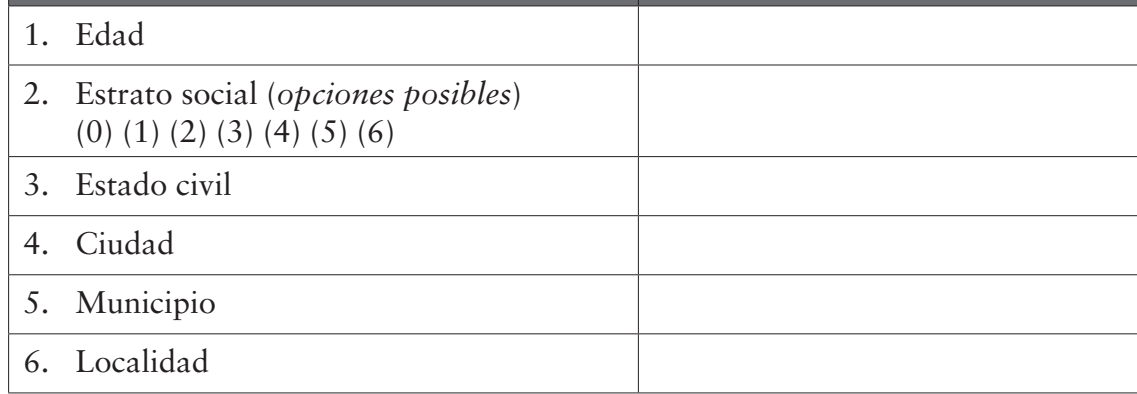




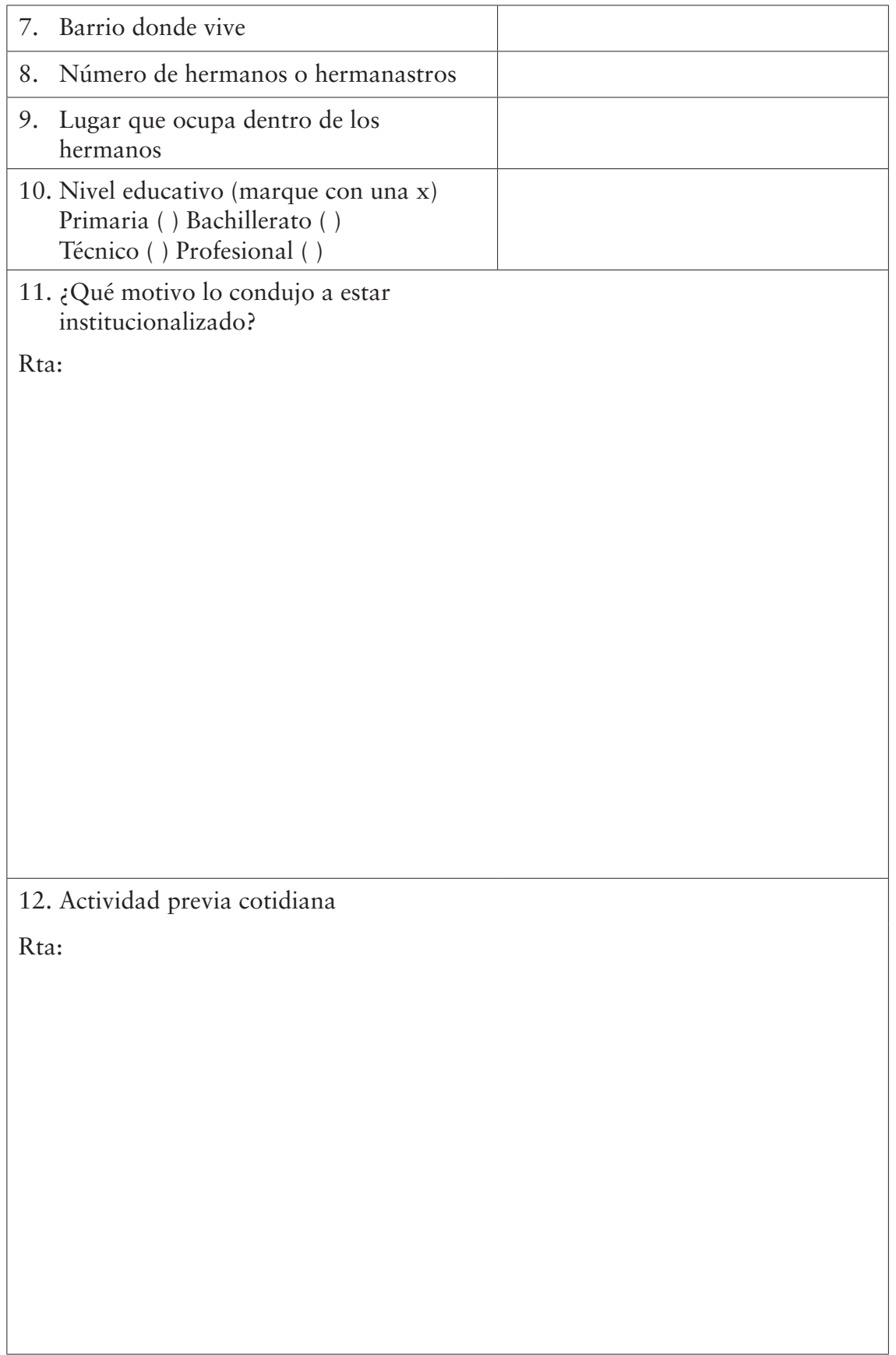




\begin{tabular}{|l|l|}
\hline $\begin{array}{l}\text { 13. ¿Es la primera vez que se encuentra } \\
\text { institucionalizado? sí( ) no( ) }\end{array}$ & \\
\hline 14. Convive con: & \\
\hline ( ) Madre, padre y hermanos & \\
\hline ( ) Madre y hermanos & \\
\hline ( ) Padre y hermanos & \\
\hline ( ) Abuelos & \\
\hline ( ) Tios y primos & \\
\hline ( ) Otros: especifique con quienes. & \\
\hline $\begin{array}{l}\text { 15. ¿Sabe qué significa justicia restaurativa? } \\
\text { si( ) no( ) }\end{array}$ \\
Si respondió sí, escriba qué siginifica justicia restaurativa: \\
Rta. \\
\end{tabular}




\begin{tabular}{|c|c|c|c|c|c|}
\hline No. & AFIRMACIÓN & 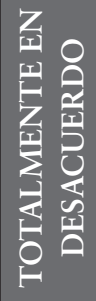 & 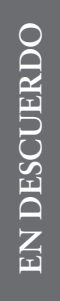 & 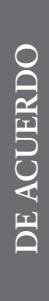 & 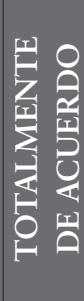 \\
\hline 1 & $\begin{array}{l}\text { Ahora que estoy recluido deseo remediar el daño } \\
\text { que causé. }\end{array}$ & & & & \\
\hline 2 & $\begin{array}{l}\text { Si viera a la persona que le cause daño le ofrecería } \\
\text { disculpas. }\end{array}$ & & & & \\
\hline 3 & $\begin{array}{l}\text { Tengo la disposición para perdonar cuando alguien } \\
\text { me ofende. }\end{array}$ & & & & \\
\hline 4 & $\begin{array}{l}\text { Reflexiono sobre cómo la infracción que cometí } \\
\text { afecta a mi familia. }\end{array}$ & & & & \\
\hline 5 & La infracción que cometía pudo afectar a mis padres. & & & & \\
\hline 6 & $\begin{array}{l}\text { Estoy dispuesto a encontrarme con la persona } \\
\text { a la que ofendí y responsabilizarme de mi } \\
\text { comportamiento. }\end{array}$ & & & & \\
\hline 7 & Quien causa un daño lo debe reparar. & & & & \\
\hline 8 & $\begin{array}{l}\text { Ahora me he dado cuenta del impacto que generó } \\
\text { mi infracción. }\end{array}$ & & & & \\
\hline 9 & Se justifica cometer un delito. & & & & \\
\hline 10 & $\begin{array}{l}\text { Me siento importante cuando he causado daño } \\
\text { a otra persona. }\end{array}$ & & & & \\
\hline 11 & $\begin{array}{l}\text { Me siento orgulloso de haber ingresado a esta } \\
\text { institución }\end{array}$ & & & & \\
\hline 12 & $\begin{array}{l}\text { Puedo pedir perdón a la(s) víctima(s) de mi } \\
\text { infracción. }\end{array}$ & & & & \\
\hline 13 & $\begin{array}{l}\text { Propondría estrategias para mejorar mi conducta } \\
\text { en el futuro con el fin de no volver a estar privado } \\
\text { de la libertad. }\end{array}$ & & & & \\
\hline 14 & $\begin{array}{l}\text { La forma de reparar el daño debe ser proporcional } \\
\text { al delito cometido. }\end{array}$ & & & & \\
\hline 15 & $\begin{array}{l}\text { Parte de la solución del problema es tener } \\
\text { conciencia de la responsabilidad que tuve en } \\
\text { los hechos. }\end{array}$ & & & & \\
\hline 16 & $\begin{array}{l}\text { Estoy dispuesto a participar en la solución del } \\
\text { problema en el cual me encuentro actualmente. }\end{array}$ & & & & \\
\hline
\end{tabular}




\begin{tabular}{|c|c|c|c|c|c|}
\hline No. & AFIRMACIÓN & 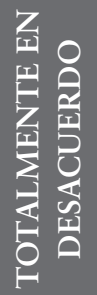 & $\begin{array}{l}0 \\
\frac{2}{2} \\
\frac{2}{2} \\
0 \\
0 \\
\frac{1}{0} \\
z \\
z=1\end{array}$ & 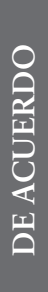 & 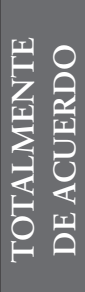 \\
\hline 17 & $\begin{array}{l}\text { Tengo interés en hablar con otros compañeros para } \\
\text { contarles la importancia que tiene reconocer los } \\
\text { delitos cometidos. }\end{array}$ & & & & \\
\hline 18 & $\begin{array}{l}\text { Considero que es posible resolver pacíficamente los } \\
\text { conflictos. }\end{array}$ & & & & \\
\hline 19 & Soluciono mis conflictos con agresión. & & & & \\
\hline 20 & $\begin{array}{l}\text { Quisiera llegar a acuerdos con las personas a las } \\
\text { que les he causado daño. }\end{array}$ & & & & \\
\hline 21 & Cuando me ofenden, respondo ofendiendo también. & & & & \\
\hline 22 & $\begin{array}{l}\text { Estoy dispuesto a participar en espacios donde se } \\
\text { toman decisiones por el bienestar común. }\end{array}$ & & & & \\
\hline 23 & Estoy dispuesto a hacer trabajo comunitario. & & & & \\
\hline 24 & Es importante para mí reconocer el daño que causé. & & & & \\
\hline 25 & Estoy dispuesto a pedir perdón. & & & & \\
\hline 26 & Quiero reconciliarme con quienes he lastimado. & & & & \\
\hline 27 & $\begin{array}{l}\text { Tengo la expectativa de poder reparar el daño que } \\
\text { causé para ser mejor persona. }\end{array}$ & & & & \\
\hline 28 & He pensado en formas de reparar mi error. & & & & \\
\hline 29 & $\begin{array}{l}\text { Me gustaría estar haciendo actividades en beneficio } \\
\text { de mi comunidad como pago por mi error. }\end{array}$ & & & & \\
\hline 30 & $\begin{array}{l}\text { Estoy dispuesto a trabajar como forma de reparar } \\
\text { el delito que cometí. }\end{array}$ & & & & \\
\hline 31 & $\begin{array}{l}\text { Espero que mi familia me apoye en lo que voy a } \\
\text { reparar. }\end{array}$ & & & & \\
\hline 32 & $\begin{array}{l}\text { Es bueno contar con apoyo comunitario en } \\
\text { procesos de reparación. }\end{array}$ & & & & \\
\hline 33 & $\begin{array}{l}\text { Me comprometo a no volver a hacer lo que me } \\
\text { trajo acá, a arreglar lo que hice contando con el } \\
\text { apoyo de otros. }\end{array}$ & & & & \\
\hline 34 & $\begin{array}{l}\text { Deseo conocer nuevas alternativas que me permitan } \\
\text { sentir que reparé el daño. }\end{array}$ & & & & \\
\hline
\end{tabular}




\section{Anexo 2}

\section{Formato de validación jueces expertos: instrumento que pretende evaluar la actitud hacia la justicia restaurativa en jóvenes vinculados al SRPA}

Estimado evaluador:

A continuación encontrará un formato en el cual se pretenden evaluar los ítems que se han construido con el fin de medir las actitudes hacia la justicia restaurativa.

Para tal efecto se solicita tener en cuenta los siguientes criterios:

1. Claridad: hace referencia a aspectos relacionados con la redacción y la construcción gramatical de cada una de las afirmaciones que componen el instrumento, en relación al objetivo de medición.

2. Pertinencia: hace alusión al grado de correspondencia o coherencia entre lo que evalúa el reactivo y el constructo a evaluar con relación al propósito del instrumento.

3. Suficiencia: aporte o contribución individual del ítem a la comprensión del constructo a evaluar, de forma que los ítems que la conforman sean suficientes y necesarios para su medición.

4. Ubicación: se refiere al orden lógico en el que se ubica cada ítem con relación a las al instrumento.

5. Relación con el constructo.

Actitud hacia la justicia restaurativa:

En el caso de esta investigación se han entendido la actitud hacia la justicia restaurativa como una predisposición aprendida para responder coherentemente de manera favorable o desfavorable la justicia restaurativa, la cual es una respuesta evolutiva al delito que respeta la dignidad y la igualdad de todas las personas, favorece el entendimiento y promueve la armonía social mediante la recuperación de las víctimas, los delincuentes y las comunidades; de igual forma es un proceso en el que la víctima, el delincuente y cuando proceda, cualesquiera otras 
personas o miembros de la comunidad afectados por un delito, participen de forma activa en la resolución de cuestiones derivadas del delito, por lo general con la ayuda de un facilitador.

Para efectos de la evaluación cuantitativa de los reactivos que componen el instrumento, es necesario adjudicar un valor a cada uno en los criterios anteriormente descritos, así:

1. Claridad: donde (1) Es claro, (2) No es claro.

2. Pertinencia: donde (1) Es pertinente, (2) No es pertinente.

3. Suficiencia: donde (1) Es suficiente (2) Es insuficiente.

4. Ubicación: donde (1) Adecuada, (2) Inadecuada.

5. Relación con el constructo: Observaciones

Con relación a la estructura del instrumento en general, se solicita evaluar aspectos tales como:

1. Formato de prueba: hace referencia a la apariencia física del instrumento, en términos de su estructura.

2. Extensión del instrumento: se refiere a qué tan adecuada es la cantidad de afirmaciones que componen el instrumento.

3. Escala utilizada: se desea juzgar la conveniencia de la escala utilizada dentro del instrumento, la cual es de tipo likert (4 opciones) - (totalmente en desacuerdo con el ítem, en desacuerdo con el ítem, de acuerdo con el ítem, totalmente de acuerdo con el ítem.

Estimado juez experto a continuación encontrará cada uno de los ítems que componen la parte socio demográfica inicial del instrumento, por favor colocar en frente si se tiene alguna sugerencia frente a las preguntas o si se tienen nuevas afirmaciones que se deseen sugerir. 


\section{DESCRIPCIÓN}

\section{OBSERVACIONES}

1. Edad

2. Estrato social (opciones posibles) (0) (1) (2) (3) (4) (5) (6)

3. Barrio donde vive

4. Número de hermanos

5. Lugar que ocupa dentro de los hermanos

6. Nivel educativo (marque con una $\mathrm{x}$ ) Primaria ( ) Bachillerato ( )

7. ¿Qué motivo lo condujo a estar institucionalizado?

Rta:

8. Actividad previa cotidiana

Rta: 


\section{DESCRIPCIÓN}

OBSERVACIONES

9. ¿Es la primera vez que se encuentra institucionalizado? Sí( ) $\mathrm{No}$ ( )

10. Convive con: (marque con una $\mathrm{x}$ las opciones correctas)

( ) Madre, padre y hermanos

( ) Madre y hermanos

( ) Padre y hermanos

( ) Abuelos

( ) Tíos y primos

( ) Otros: especifique con quienes

11. ¿Sabe qué significa justicia restaurativa?

$$
\text { Sí ( ) No ( ) }
$$

En caso de responder (sí) escriba qué siginifica justicia restaurativa:

Rta.

Estimado juez experto a continuación encontrará cada uno de los ítems que componen el instrumento que pretende medir las actitudes hacia la justicia restaurativa, para efectos de la evaluación de la calidad técnica del instrumento, amablemente se solicita marcar con una (X), de acuerdo a la escala anteriormente presentada y colocar las observaciones o sugerencias que se consideren pertinentes con relación a cada ítem propuesto. 


\begin{tabular}{|c|c|c|c|c|c|c|}
\hline No. & AFIRMACIÓN & 䆣 & 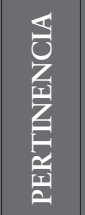 & 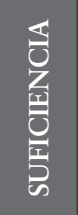 & 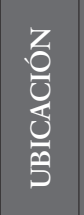 & OBSERVACIONES \\
\hline & & 12 & \begin{tabular}{|l|l|}
1 & 2
\end{tabular} & 12 & 12 & \\
\hline 1 & $\begin{array}{l}\text { Ahora que estoy recluido } \\
\text { deseo remediar el daño que } \\
\text { causé. }\end{array}$ & & & & & \\
\hline 2 & $\begin{array}{l}\text { Si viera a la persona a } \\
\text { la que le causé daño, le } \\
\text { ofrecería disculpas. }\end{array}$ & & & & & \\
\hline 3 & $\begin{array}{l}\text { Cuando alguien me ofende, } \\
\text { perdono. }\end{array}$ & & & & & \\
\hline 4 & $\begin{array}{l}\text { Reflexiono sobre cómo } \\
\text { mis errores afectan a mi } \\
\text { familia. }\end{array}$ & & & & & \\
\hline 5 & $\begin{array}{l}\text { Lo que hice afecta a mis } \\
\text { padres. }\end{array}$ & & & & & \\
\hline 6 & $\begin{array}{l}\text { Estoy dispuesto a } \\
\text { encontrarme con } \\
\text { quien ofendí con mi } \\
\text { comportamiento y } \\
\text { responsabilizarme del } \\
\text { mismo. }\end{array}$ & & & & & \\
\hline 8 & $\begin{array}{l}\text { Quien comete un delito } \\
\text { debe arreglar lo que ha } \\
\text { dañado. }\end{array}$ & & & & & \\
\hline
\end{tabular}




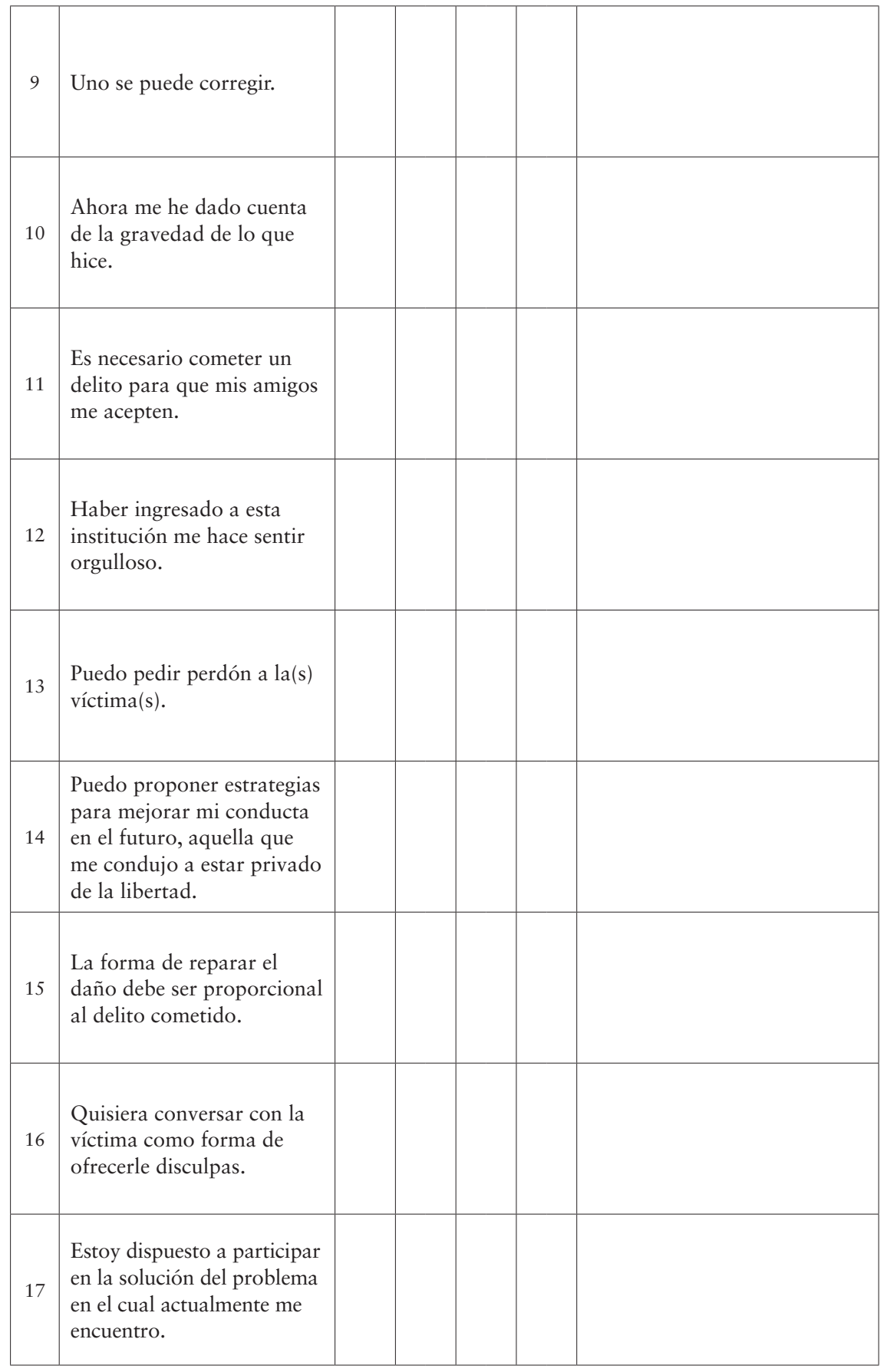




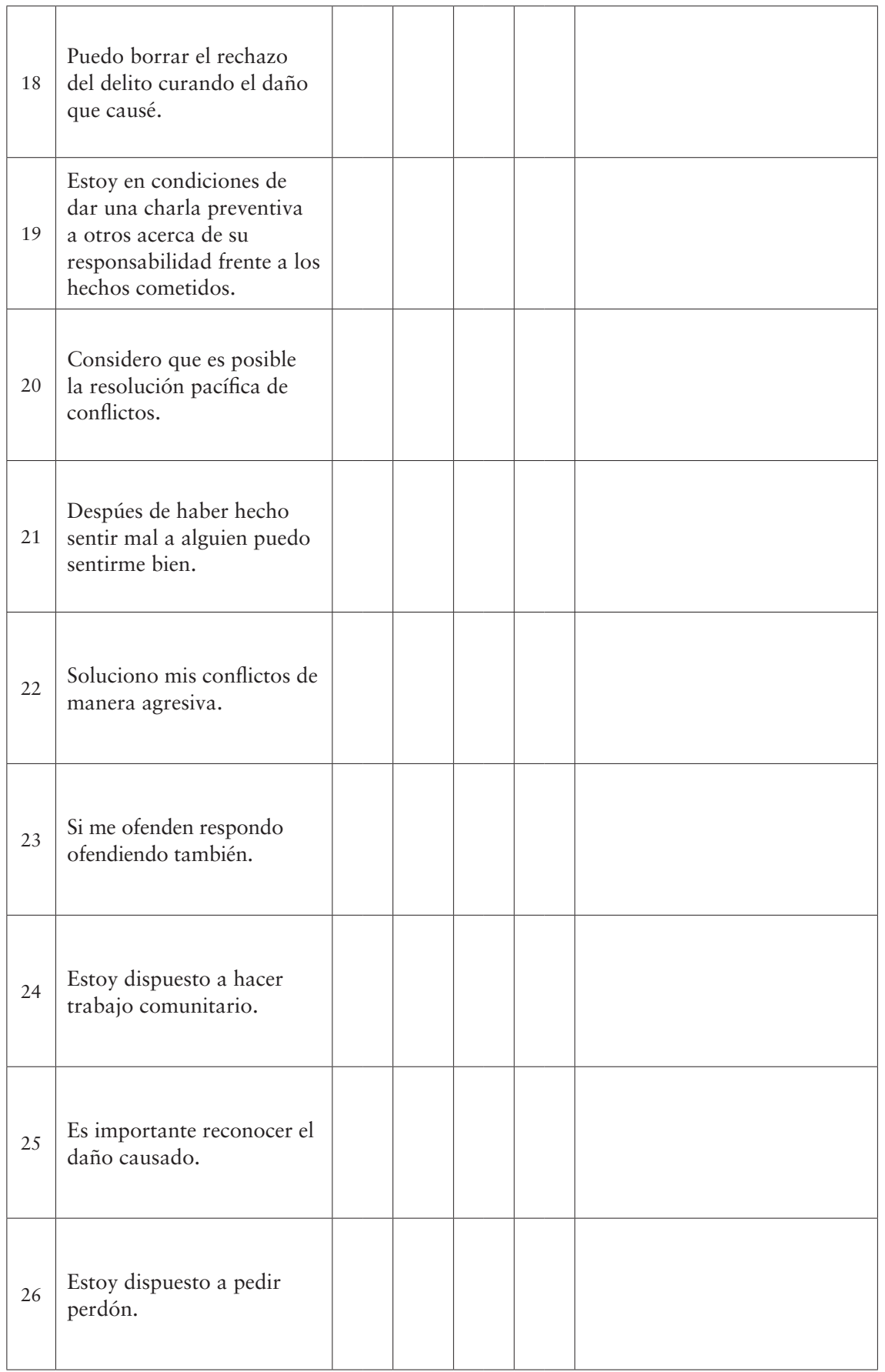




\begin{tabular}{|c|c|c|c|c|c|c|}
\hline No. & AFIRMACIÓN & 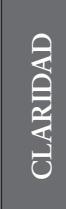 & 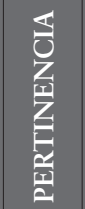 & 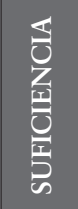 & $\begin{array}{l}z \\
0 \\
0 \\
0 \\
0 \\
0 \\
\text { s. }\end{array}$ & OBSERVACIONES \\
\hline & & $1 \mid 2$ & \begin{tabular}{|l|l|}
1 & 2
\end{tabular} & \begin{tabular}{|l|l|l}
1 & 2
\end{tabular} & $1 \mid 2$ & \\
\hline 27 & $\begin{array}{l}\text { Quisiera reconciliarme con } \\
\text { quienes he lastimado. }\end{array}$ & & & & & \\
\hline 28 & $\begin{array}{l}\text { Me gustaría contarle a } \\
\text { otros mi experiencia. }\end{array}$ & & & & & \\
\hline 29 & $\begin{array}{l}\text { Soy corresponsable de los } \\
\text { hechos por los cuales estoy } \\
\text { en la institución. }\end{array}$ & & & & & \\
\hline 30 & $\begin{array}{l}\text { Podría reunirme con la } \\
\text { persona que me denunció. }\end{array}$ & & & & & \\
\hline 31 & $\begin{array}{l}\text { Puedo volver a estar } \\
\text { institucionalizado luego } \\
\text { de esta medida. }\end{array}$ & & & & & \\
\hline 32 & $\begin{array}{l}\text { Deseo cambiar el daño } \\
\text { que causé. }\end{array}$ & & & & & \\
\hline 33 & $\begin{array}{l}\text { Reparar el daño que causé } \\
\text { me hace mejor persona. }\end{array}$ & & & & & \\
\hline
\end{tabular}

